\title{
A contemporaneidade da Pedagogia da Autonomia de Paulo Freire frente ao "Escola Sem Partido"
}

\author{
The contemporaneity of Paulo Freire's Pedagogy of Autonomy face \\ to "Non-Partisan School"
}

\section{La contemporaneidad de la Pedagogía de la Autonomía de Paulo} Freire ante el "Escuela Sin Partido"

\author{
Jennifer Caroline de Sousa ${ }^{1}$ \\ https://orcid.org/0000-0003-270I-1263 \\ Thiago Araujo Santos² \\ https://orcid.org/0000-0002-1305-0301
}

Resumo: A incursão de uma onda neoconservadora no Brasil contemporâneo carrega como uma de suas expressões para o campo educacional o "Escola Sem Partido" (ESP), um movimento político-ideológico que tem inspirado uma série de projetos de lei e propostas de emenda aos Planos Municipais, Estaduais de Educação e à própria Lei de Diretrizes e Bases da Educação Nacional. Neste artigo propomos um retorno ao pensamento freireano para analisar o Anteprojeto de Lei Federal e Minuta de Justificação que propõe instituir o "Programa Escola sem Partido". Com base no levantamento do status dos projetos apresentados em todo o país e na análise de conteúdo do documento citado, compreendemos que o ESP obscurece a sua própria ideologia tendo em vista: a desfiguração da identidade docente e do papel da educação escolar na formação dos indivíduos; o favorecimento da privatização da educação brasileira; e a consolidação de uma nova fração da classe dominante no país.

Palavras-chave: Escola Sem Partido. Ideologia. Pedagogia da Autonomia.

\begin{abstract}
The neoconservative movement at contemporary Brazil supports as one of its expressions for the educational field the "Non-Partisan School", a political-ideological movement has inspired a series of law projects to modify local and state plans of Education and the major law of National System of Education ("LDB") itself. Here, we came back to principles of Freirean Education to analyze the project of federal law and its draft justification that purposes to found the "Non-Partisan School Program". By the survey of the status of the presented law projects and analysis of the content of federal law project, we understand that the "Non-Partisan School" hides its own ideology aiming to: institutionalize an educational politics that devastates the teacher
\end{abstract}

\footnotetext{
' Doutoranda em Educação pelo Programa de Pós-Graduação em Educação da Universidade de São Paulo. E-mail: jennifercsousa@usp.br.

${ }^{2}$ Doutor em Geografia Humana pela Universidade de São Paulo. Professor Adjunto da Universidade Federal de Mato Grosso do Sul, Campus Três Lagoas, atuante nos cursos de Graduação e Pós-Graduação em Geografia. Email: thiago.a@ufms.br
}

Olhar de professor, Ponta Grossa, v. 24, p. I-24, e-15788.039, 202 I.

Disponível em <https://revistas2.uepg.br/index.php/olhardeprofessor> 
identity in order to repeal the role of the scholar education in the civil formation; advanced of the privatization of the Brazilian education; and strength a new quota of dominant group in the country.

Keywords: Non-Partisan School. Ideology. Pedagogy of Autonomy.

Resumen: La nueva ola conservadora en el Brasil contemporáneo tiene como una de sus expresiones para el campo educacional el "Escuela sin Partido", un movimiento político-ideológico que ha inspirado una serie de proyectos de ley y enmiendas parlamentarias a los Planes Municipales, Estaduales de la Educación y la propia Ley máxima de la Educación Brasileña (“LDB”). En este artículo, proponemos una vuelta al pensamiento freireano para analizar el Anteproyecto de Ley Federal y Minuta de Justificación que instituye el "Programa Escuela sin Partido". Basados en el levantamiento del status de los proyectos presentados en todo el país y en el análisis del contenido del documento citado, comprendemos que el ESP oscurece su propia ideología con el fin de: desfigurar la identidad docente y el rol de la educación escolar en la formación de los individuos; favorecer la privatización de la educación brasileña; y consolidar una nueva fracción de la clase dominante en el país.

Palabras-clave: Escuela Sin Partido. Ideología. Pedagogía de la Autonomía.

\section{Introdução}

O contexto de emergência do "Escola Sem Partido" (ESP), cujos projetos constituem-se como o interesse central de nossa reflexão, é perpassado por uma combinação complexa de fatores. De forma mais ampla, o irracionalismo pós-moderno, visão de mundo que ganha corpo no ocidente a partir de meados dos anos 1970 (HARVEY, 2012), é fortemente marcado pelo relativismo do conhecimento, questionamento da autoridade científica e pela negação da legitimidade cultural das instituições modernas, entre as quais a escola. Se, por um lado, o caráter contestatório dessas ideias parece apontar para uma negação radical do status quo por meio da rejeição dos fundamentos de sua racionalidade, por outro, na realidade brasileira, sua narrativa associa-se ao arsenal discursivo de frações de classe que buscam legitimar seus projetos neoconservadores, avançando sobre os espaços institucionais com medidas profundamente regressivas.

Nesse cenário, são questionadas e rechaçadas a obra e a vida de Paulo Freire (1921-1997), educador e filósofo brasileiro da educação, reconhecido mundialmente por sua defesa em favor de uma pedagogia libertadora. Concordamos com Ratier (2016) quando afirma que, embora a bibliografia freireana já tenha sido traduzida para mais de vinte línguas, rendendo ao pernambucano o título de doutor honoris causa em 4I universidades, incluindo Oxford, Harvard e Cambridge, tais fatos não implicam que estudar Paulo Freire signifique aceitar indubitavelmente todas as suas afirmações e premissas. No entanto, exige considerar a distinção de seu legado, sejam quais forem os princípios e vieses políticos assumidos. Na contramão disso, prestes a comemorarmos o centenário de seu nascimento, assistimos a seu pensamento ser combatido pelos agentes do ESP, que, não à toa, o leem como uma ameaça.

É, pois, nesse sentido, que a confrontação entre os distintos ideais para a educação - os de Freire e os do ESP - e as diferentes compreensões sobre a prática docente constitui-se, a nosso ver, 
uma tarefa pertinente, e a ela nos voltamos no presente artigo. Apoiados nos pressupostos freireanos constantes em Pedagogia da Autonomia (1996), nos propomos a explorar e analisar o Anteprojeto de Lei Federal e Minuta de Justificação do Escola sem Partido.

Tal empreendimento não consiste tão somente em expor os traços que definem as diferentes visões de mundo, de modo desinteressado, contemplativo, como recurso que evidenciaria a pluralidade de interpretações sobre o campo educacional. Trata-se, mais do que isso, de reivindicar o legado freireano como um aporte necessário à defesa teórico-política de uma "escola cidadã": democrática, plural, coerente e comprometida com a liberdade e com a justiça social. Se, por um lado, o projeto moderno tem demonstrado insuficiência na realização de suas promessas, particularmente a de emancipação humana, por outro, a defesa crítica de algumas de suas conquistas, ainda que parciais, estando entre elas a escola, mostra-se uma postura necessária para a radicalização democrática numa perspectiva libertadora.

O texto está organizado em sete seções. Na primeira, contextualizamos e caracterizamos o movimento "Escola Sem Partido" através do resgate de seu histórico e fundamentos e do levantamento acerca do número e do status dos projetos de lei e propostas de emenda inspirados no ESP. Na segunda, passamos ao referencial freireano, com destaque para a Pedagogia da Autonomia (1996), cujas bases suportaram em grande medida a análise realizada. Na terceira, descrevemos os caminhos metodológicos desta pesquisa, caracterizada por seu caráter qualitativo e pelo emprego dos métodos da análise documental e da análise de conteúdo. Na quarta, exploramos o "Anteprojeto de Lei Federal e Minuta de Justificação" e apresentamos as informações extraídas a partir da leitura, decodificação e categorização dos elementos que o constituem. Nas duas seções seguintes, passamos à análise propriamente do referido documento, problematizando suas implicações para o campo educacional, especialmente no que se refere à desfiguração do papel da educação escolar e da identidade docente, sustentada no esvaziamento da autonomia em sala e na pretensa neutralidade político-ideológica do ato educativo. Ao final, tecemos algumas considerações sobre o potencial dos fundamentos da pedagogia freireana para o enfrentamento dos desafios impostos pelo recrudescimento do conservadorismo no contexto educacional brasileiro.

\section{“Escola Sem Partido”: contexto e caracterização}

A escola tal qual a conhecemos foi fundada sob a racionalidade iluminista do século XIX, que, ao orientar a entrada da humanidade na era moderna, destituiu a velha cultura oral e comunitária que antecedeu as revoluções industrial e urbana (FORQUIN, 1993). A concepção subjacente à propulsão da escolarização em massa era a de que a sociedade burguesa emergente só poderia ascender ao poder

Olhar de professor, Ponta Grossa, v. 24, p. I-24, e-15788.039, 202 I.

Disponível em <https://revistas2.uepg.br/index.php/olhardeprofessor> 
com a erradicação da ignorância, em que os então "súditos" do Antigo Regime se transformariam em “cidadãos”. Assim, o caminho para lograr tal objetivo era o ensino formal (MELO; TOSTA, 2008).

Assumindo a definição de Saviani (1996, p. I3I) de que a educação é "uma atividade mediadora no seio da prática global" e, portanto, "sempre referida a uma sociedade concreta, historicamente situada", é razoável compreender por que a escola afeta e é afetada pelas demais manifestações sociais, as quais são promovidas por grupos com interesses antagônicos (LIBÂNEO, 20I4). O que disso resulta na sociedade contemporânea é a ressignificação constante de suas instituições, que, no caso da escola, tem seus valores e papeis frequentemente revisitados e contestados (MELO; TOSTA, 2008).

No caso do Brasil do início do século XXI, nos diz Saviani (2018), o que se vê é que a educação como "um direito de todos e dever do Estado" outrora preconizado pelos princípios iluministas, hoje é tida como "um dever de todos" dentro do ideário neoliberal do Estado mínimo, este que se ocupa do controle e da avaliação da educação enquanto transfere para a "sociedade" as responsabilidades pela sua manutenção e qualidade. No entanto, é premente ressaltar que, frente à desigualdade socioeconômica presente na sociedade brasileira, a educação é gerenciada sobremaneira pela classe dominante que, como alerta Saviani (1996), se compõe de múltiplas frações que disputam entre si a hegemonia.

Um exemplo emblemático dessa situação para a educação brasileira é a articulação do movimento "Escola Sem Partido" (ESP), fundado em 2004 pelo advogado e Procurador do Estado de São Paulo Miguel Nagib. Em 20I4, esse se notabilizou com a tramitação de projetos de lei nos níveis municipais, estaduais e federais inspirados nas suas pautas. Em 2015, Nagib criou a "Associação Escola Sem Partido" para ter uma entidade jurídica com a qual pudesse recorrer à Justiça em casos de denúncia perpetrados pelo ESP (MANHAS, 20I6).

A atuação do ESP se dá principalmente através de seu site ${ }^{3}$, que funciona como um meio de divulgação de suas ideias para a população em geral e de instrumentalização para denúncias de "práticas de doutrinação" que membros da sociedade identifiquem no ambiente escolar e acadêmico. Dessa forma, o ESP dissemina e respalda procedimentos de vigilância, controle e criminalização das atividades desenvolvidas no âmbito da educação formal. Segundo sua concepção, os docentes têm se utilizado da

\footnotetext{
${ }^{3}$ Disponível em: www.escolasempartido.org. Acesso em: 01 jun. 2020. Na aba "Conheça o Programa Escola sem Partido" é possível acessar uma lista de seis deveres do professor em sala de aula que se referem a não propagar nem permitir que se viole o que propõe a organização. Fazendo alusão à Constituição Federal e à Convenção Americana sobre Direitos Humanos, seguem com um texto "Por uma lei contra o abuso da liberdade de ensinar", em que acusam: "a pretexto de 'construir uma sociedade mais justa' ou de 'combater o preconceito', professores de todos os níveis vêm utilizando o tempo precioso de suas aulas para 'fazer a cabeça' dos alunos sobre questões de natureza político-partidária, ideológica e moral”'.
}

Olhar de professor, Ponta Grossa, v. 24, p. I-24, e-II5788.039, 202I.

Disponível em <https://revistas2.uepg.br/index.php/olhardeprofessor> 
audiência cativa dos estudantes para fazer propaganda ideológica, política e partidária e têm usurpado o papel dos pais no que se refere à educação religiosa e moral de seus filhos.

Ainda que denominado por Nagib como "uma associação informal, independente, sem fins lucrativos e sem qualquer espécie de vinculação política, ideológica ou partidária”, para Algebaile (2017), o ESP deveria ser qualificado como uma organização. Primeiramente porque opera através de um programa de ação sustentado por parlamentares que têm ampliado de modo sistemático as bandeiras do ESP ao tornarem-se signatários de projetos baseados nos modelos disponibilizados pela organização; segundo, porque o ESP tem se unido a setores da mídia, segmentos religiosos, políticopartidários e acadêmicos e, a partir dessa base, ganhado forças e estabelecido frentes de atuação variadas. Dessa forma, para a autora, estamos diante de um "organismo especializado, internamente centralizado e externamente vinculado, por sua instrumentalidade, a uma vertente político-partidária mais diversificada na sua composição" (ALGEBAILE, 20I7, p. 66).

Brait (2016) afirma que os Projetos de Lei (PL) 2974/2014 e 867/2014 apresentados, respectivamente, por Flávio Bolsonaro (Republicanos-RJ), senador pelo Rio de Janeiro, e Carlos Bolsonaro (Republicanos-RJ), vereador da Câmara Municipal do Rio de Janeiro, impulsionaram a proposição de uma série de projetos de teor similar pelo país. No âmbito federal, o PL 7/80/2014, de Erivelton Santana (PATRI-BA), arquivado no final de 2018, também fomentou a submissão de outros que foram apensados a ele, como o PL 867/20I5, do senador Izalci Lucas (PSDB-DF) e o PLS 193/2016, do ex-senador Magno Malta (PR-ES), que propuseram incluir na Lei de Diretrizes e Bases da Educação Nacional (LDB n 9394/1996) o "Programa Escola Sem Partido".

Até o momento, no Brasil, 208 projetos inspirados no "Escola sem Partido" foram enviados ou estão em apreciação nas Câmaras de Vereadores, Assembleias Legislativas e no Congresso Nacional, dos quais 57 estão em vigor ou foram sancionados, 53 estão em tramitação, 4l foram arquivados, 39 foram retirados, vetados, derrubados, recusados, rejeitados ou suspensos e 18 têm seu status desconhecido 4 .

Na Tabela I é possível observar que São Paulo, Paraná, Rio de Janeiro e Rio Grande do Sul figuram entre as unidades federativas que possuem maior número de projetos submetidos. Não foram encontrados projetos provenientes dos estados do Acre e de Roraima.

\footnotetext{
${ }^{4} \mathrm{O}$ levantamento dos projetos foi obtido de um blog gerenciado por uma professora e pelo coletivo "Professores Contra o Escola Sem Partido", em que os autores disponibilizam um "Mapa dos Projetos Escola Sem Partido no Brasil” em: https://pesquisandooesp.wordpress.com/mapa-dos-projetos/. Para conhecer o status de tramitação dos projetos utilizamos os dados mais atuais da "Frente Nacional Escola Sem Mordaça", que podem ser consultados em: https://www.escolasemmordaca.org.br/?page_id=4218. Acesso em: 02 jun. 2020.
}

Olhar de professor, Ponta Grossa, v. 24, p. I-24, e-15788.039, 202 I.

Disponível em <https://revistas2.uepg.br/index.php/olhardeprofessor> 
A contemporaneidade da Pedagogia da Autonomia de Paulo Freire frente ao "Escola Sem Partido"

Tabela I - Quantidade de e status dos projetos inspirados no “Escola Sem Partido” por unidade federativa

(2014-2019)

\begin{tabular}{|c|c|c|c|c|c|c|c|c|c|c|c|c|}
\hline \multirow{2}{*}{$\begin{array}{l}\text { Unidade } \\
\text { federativa }\end{array}$} & \multicolumn{12}{|c|}{ Status dos projetos "Escola sem Partido" } \\
\hline & AR & AS & $\mathrm{DE}$ & $\mathrm{RC}$ & RJ & RT & SD & SU & TR & VE & $\mathrm{VI}$ & $\begin{array}{c}\text { Tot } \\
\text { al }\end{array}$ \\
\hline Alagoas & - & - & - & - & - & - & - & 1 & - & - & - & $\mathrm{I}$ \\
\hline Amapá & - & - & - & - & - & - & $\mathrm{I}$ & - & - & - & - & I \\
\hline Amazonas & - & - & - & - & - & - & - & $\mathrm{I}$ & 2 & - & - & 3 \\
\hline Bahia & - & I & - & - & - & - & I & - & 2 & - & 2 & 6 \\
\hline Ceará & - & - & - & - & $\mathrm{I}$ & I & $\mathrm{I}$ & - & $\mathrm{I}$ & - & 2 & 6 \\
\hline Distrito Federal & - & - & - & - & - & - & - & - & 2 & - & - & 2 \\
\hline Espírito Santo & 3 & - & - & - & - & I & - & I & 2 & I & 3 & II \\
\hline Goiás & 3 & 2 & - & - & - & - & - & $\mathrm{I}$ & - & - & - & 6 \\
\hline Maranhão & - & - & - & - & - & - & - & - & I & - & - & 1 \\
\hline Mato Grosso & 2 & - & - & - & I & - & - & - & - & - & I & 4 \\
\hline Mato Grosso do Sul & I & I & - & - & I & & I & - & 2 & I & - & 7 \\
\hline Minas Gerais & - & 2 & - & - & - & 2 & $\mathrm{I}$ & - & 5 & - & $\mathrm{I}$ & II \\
\hline Pará & - & - & - & $\mathrm{I}$ & - & - & I & - & - & - & - & 2 \\
\hline Paraíba & 3 & I & - & - & I & - & I & - & - & I & 3 & 10 \\
\hline Paraná & 10 & 2 & - & I & - & 2 & 2 & I & 3 & - & 5 & 26 \\
\hline Pernambuco & 3 & 2 & - & - & - & I & 2 & - & 3 & - & 4 & 15 \\
\hline Piauí & - & - & - & - & - & - & 2 & - & - & - & - & 2 \\
\hline Rio de Janeiro & 3 & - & 2 & - & - & I & I & - & 7 & I & 4 & 19 \\
\hline $\begin{array}{l}\text { Rio Grande do } \\
\text { Norte }\end{array}$ & - & 2 & - & - & - & - & 2 & - & I & - & 3 & 8 \\
\hline Rio Grande do Sul & 8 & - & - & - & $\mathrm{I}$ & 3 & - & - & 3 & $\mathrm{I}$ & - & 16 \\
\hline Rondônia & - & - & - & - & - & - & - & - & I & - & - & I \\
\hline Santa Catarina & 3 & $\mathrm{I}$ & - & - & - & - & - & - & 5 & - & 6 & 15 \\
\hline São Paulo & 2 & I & - & - & $\mathrm{I}$ & I & 2 & 5 & 12 & I & 6 & 31 \\
\hline Sergipe & - & - & - & - & - & - & - & - & I & - & I & 2 \\
\hline Tocantins & - & I & - & - & - & - & - & I & - & - & - & 2 \\
\hline Total & $4 I$ & 16 & 2 & 2 & 6 & 12 & 18 & II & 53 & 6 & 41 & 208 \\
\hline
\end{tabular}

Legenda: $A R$ = arquivado; $A S$ = aprovado ou sancionado; $D E$ = derrubado; $R C$ = recusado; $R J$ = rejeitado; $R T$ = retirado; $\mathrm{SD}=$ status desconhecido; $\mathrm{SU}=$ suspenso; $\mathrm{TR}=$ tramitando; $\mathrm{VE}=$ vetado; $\mathrm{VI}=$ em vigor.

Fonte: Mapa dos Projetos Escola Sem Partido no Brasil e Frente Nacional Escola Sem Mordaça.

Organização: Autores, 2020.

Miguel (2016) salienta que o ESP ganha novas feições e se fortalece no Brasil a partir do momento em que une ao seu discurso "anticomunista", fundado na crença de uma suposta doutrinação político-marxista existente nas escolas, o combate à "ideologia de gênero"`. Com essa fusão, argumenta o autor, o ESP angariou para si um terreno "moral" além do "político", engendrando uma

\footnotetext{
${ }^{5}$ Em linhas gerais, essa expressão surgiu como uma designação para qualificar e contrapor os debates que giram em torno de "gênero", um conceito originado no ambiente acadêmico estadunidense dos anos 1970 que se tornou marco do movimento feminista contemporâneo e das pautas identitárias ligado ao universo LGBT (Lésbicas, Gays, Bissexuais, Transexuais ou Transgêneros) (MIGUEL, 20I6).
}

Olhar de professor, Ponta Grossa, v. 24, p. I-24, e-II5788.039, 202I.

Disponível em <https://revistas2.uepg.br/index.php/olhardeprofessor> 
disputa entre a escolarização formal e a autoridade dos preceitos e valores da família tradicional cristã. Pode-se observar a ampliação dessa agenda conservadora através da análise do conteúdo dos projetos, em que cerca de metade deles investe especificamente contra a "ideologia de gênero" ou somam a essa reivindicação a implementação do "Programa Escola Sem Partido" (Tabela 2).

Tabela 2 - Conteúdo principal dos projetos inspirados no "Escola Sem Partido"

\begin{tabular}{|c|c|}
\hline Categoria de reivindicação & $\begin{array}{c}\mathbf{N}^{\circ} \text { de } \\
\text { projetos }\end{array}$ \\
\hline Implementação do “Programa Escola Sem Partido” (ESP) & 105 \\
\hline $\begin{array}{l}\text { Combate à "ideologia de gênero" (Proibição da abordagem de temas } \\
\text { relacionados a gênero, diversidade e orientação sexual em aulas e materiais } \\
\text { didáticos) }\end{array}$ & 62 \\
\hline ESP + combate à "Ideologia de gênero" & 30 \\
\hline $\begin{array}{l}\text { Combate à "pornografia na infância" (Proibição de materiais didáticos que } \\
\text { façam alusão ao erotismo e às relações sexuais humanas) }\end{array}$ & 8 \\
\hline Total* & 205 \\
\hline
\end{tabular}

(*) Três projetos não tiveram seu conteúdo classificado em nenhuma das categorias, pois não foram encontrados disponíveis na Internet até o fechamento deste trabalho.

Fonte: Mapa dos Projetos Escola Sem Partido no Brasil e Frente Nacional Escola Sem Mordaça. Organização: Autores, 2020.

No Brasil, Miguel (2016) analisa que três vertentes reacionárias convergem para o fortalecimento do ESP: o "libertarianismo" proveniente da ideologia ultraliberal difundida por ativistas influentes no meio acadêmico estadunidense, o fundamentalismo religioso de cristãos protestantes e católicos conservadores e o antigo anticomunismo.

No caso dos "libertarianos", seus discursos são disseminados através de fundações privadas, a exemplo do Instituto Millenium, entidade sem fins lucrativos formada por intelectuais e empresários brasileiros, que já teve como um de seus integrantes, na condição de autor de artigos e doador, o próprio Miguel Nagib (ESPINOSA; QUEIROZ, 20I7), desvinculado dela após a emergência do ESP no país (BRAIT, 2016; MIGUEL, 2016).

Contudo, como ressalta Penna (2018), a ambiguidade da relação entre os discursos neoliberais e ultraconservadores se observa quando entram em cena os reformadores empresarias da educação. Se por um lado, Ihes interessa tanto quanto aos articulistas do ESP a restrição da autonomia docente haja vista o empecilho que ela constitui para o avanço da lógica privatista na educação, por outro, o esvaziamento do potencial educacional da escola e da possibilidade de introdução de determinados valores e competências (i.e., tais como as socioemocionais, assim propostas pelo Instituto Ayrton Senna) colidem frontalmente com o núcleo duro de reivindicações do ESP.

Com relação ao fundamentalismo religioso, Oro (2003) resgata na história que o aparecimento da classe religiosa no cenário político brasileiro se deu a partir do final da década de 1980 e atravessou 
os anos 1990 e 2000 em ascendência no número de vereadores, deputados estaduais e federais e senadores eleitos, candidatos esses egressos da própria Igreja Universal do Reino de Deus (IURD) ou apoiados por ela. Na visão do autor, a atuação política da IURD, considerando os períodos do governo FHC e Lula, se concretizou de modo "sofisticado", pois seus candidatos se distribuíam pelos diferentes partidos, o que lhe teria proporcionado maior poder de barganha política.

No governo Bolsonaro, Almeida (2019) avalia que parte significativa desse segmento religioso, junto com representantes do setor mais conservador da Igreja Católica, como recorda Miguel (2016), configuram um processo social mais amplo que articula, ao menos e em níveis diferentes, quatro linhas de forças sociais: economicamente liberal, moralmente reguladora, securitariamente punitiva e socialmente intolerante.

Por fim, a estridência do discurso anticomunista no Brasil contemporâneo é peremptoriamente proferida pelos membros do ESP, que conta com forte respaldo do governo vigente e também com figuras centrais de movimentos ou partidos políticos de direita ou de centro-direita, como o Movimento Brasil Livre (MBL) e o Partido da Social Democracia Brasileira (PSDB). Nesse contexto, Miguel (2016) afirma que o Partido dos Trabalhadores (PT) foi enquadrado como a encarnação do comunismo no Brasil, havendo uma notável sobreposição entre anticomunismo e antipetismo que os tornou, na prática, sinônimos.

É, pois, em meio à onda neoconservadora que o legado do educador pernambucano Paulo Freire foi e é sistematicamente considerado um fundamento para a doutrinação ideológica e políticopartidária nas escolas, sendo propagada, por isto, sua dissolução. Sob tal solo persecutório, o atual presidente da república cogitou em uma entrevista 6 retirar o título de Patrono da Educação Brasileira concedido a Paulo Freire pela Lei $n^{\circ} 12.612 / 2012$, durante o primeiro mandato da presidenta Dilma Rousseff. Embora se observe a empreitada de desmerecer e marginalizar a importância de seus escritos para compreender o fenômeno educacional no mundo e, particularmente, na América Latina, a notoriedade de Paulo Freire é identificada pela tradução de seus livros nas mais variadas línguas e pela existência de tantos outros que retratam sua vida e obra (GADOTTI, 1996; BEISIEGEL, 20I0; ZITKOSKI, 20I0; SOUZA, 20I5; ARAÚJO FREIRE, 20I7).

\footnotetext{
${ }^{6}$ No canal "Programa da Esther", da youtuber mirim Esther Castilhos, há uma entrevista concedida por Jair Bolsonaro em que o mesmo profere (no intervalo entre $11 \min 27$ s - IImin39s): "Quem sabe nós temos uma patrona [referindo-se à entrevistadora Esther] da Educação e não mais um patrono muito chato, não precisa falar quem que é, que temos até o momento. Ele vai ser mudado, estamos aguardando, esperando alguém diferente... Quem sabe seja você...". O vídeo com a entrevista pode ser consultado em: https://www.youtube.com/watch?v=8VIRBadxQxw. Acesso em: 10 set. 2019. Tramitou no Senado Federal a sugestão legislativa $n^{\circ}$ 47/2017, apresentada por Steffany Papaiano, coordenadora do movimento Direita São Paulo e apoiadora do ESP, que propunha a revogação da Lei 12.612/2012. Entretanto, foi rejeitada por Comissão em decisão terminativa.
}

Olhar de professor, Ponta Grossa, v. 24, p. I-24, e-II5788.039, 202I.

Disponível em <https://revistas2.uepg.br/index.php/olhardeprofessor> 
Em contrapartida, setores da sociedade civil têm realizado resistências frente ao avanço da agenda neoconservadora do ESP. Como exemplo, o coletivo "Professores Contra o Escola Sem Partido" (PCESP), fundado em 2015, tem acompanhado a tramitação dos projetos de lei apresentados nas escalas municipal, estadual e federal que se fundamentam nos princípios defendidos pela organização. Ademais, suportam em seu site ${ }^{7}$ uma lista de trabalhos acadêmicos que analisam criticamente as investidas do ESP. Por fim, articulam duas formas de mobilização: através da assinatura da carta "Defesa da Liberdade de Expressão em Sala de Aula", direcionada ao Senado, e do preenchimento de um formulário "Mobilização Contra o Escola Sem Partido", que tem os objetivos de coletar informações sobre as formas de resistência e oposição em desenvolvimento no Brasil, divulgar eventos e informar sobre projetos locais sobre o tema e fornecer um canal para que docentes relatem as ameaças e perseguições que tenham sofrido.

Como desdobramento do PCESP, em 2017, foi criado o "Movimento Escola Democrática", cujo intuito é o combate ao crescente conservadorismo educacional. Como consta em entrevista ${ }^{8}$ dada por Fernando Penna, um dos coordenadores do movimento, a ideia foi institucionalizar a experiência que o PCESP realizava desde 2015 e ampliar seu escopo de atuação, somando à oposição ao ESP outros projetos que colocassem em risco a materialização de um modelo de educação democrática.

Também foi lançada a "Frente Nacional Escola Sem Mordaça", composta por várias entidades sindicais, associações, movimentos sociais e estudantis, que visa propor estratégias e soluções para o enfrentamento das ações do ESP. Em 2016, realizaram o primeiro "Curso de Formação de Debatedores e Multiplicadores contra os projetos do Escola Sem Partido e contra a imposição de censura aos educadores", na UFRJ. Assim como o PCESP, também informam em sua plataforma a quantidade e o status de tramitação dos projetos de lei.

Essas são algumas das iniciativas que têm protagonizado a luta contra o neoconservadorismo educacional em ascensão no país. Ademais, defendemos aqui que o legado de Paulo Freire, edificado em um contexto em que o conservadorismo e o neoliberalismo já subjugavam as classes oprimidas através de uma educação bancária, reacionária e domesticadora (FREIRE, 1987), pode fortalecer a tônica da resistência ao oferecer caminhos para a compreensão e a análise das investidas do ESP sobre a educação brasileira.

\footnotetext{
7 Página do blog do coletivo "Professores Contra ○ Escola Sem Partido" disponível em: https://profscontraoesp.org. Acesso em: 20 ago. 2019.

${ }^{8}$ A entrevista completa com Fernando Penna concedida a André Antunes e publicada em 29 de junho de 2017 pela EPSJV/Fiocruz pode ser lida em: http://cdhpf.org.br/artigos/3489/. Acesso em: II set. 2019.
}

Olhar de professor, Ponta Grossa, v. 24, p. I-24, e-I5788.039, 202 I.

Disponível em <https://revistas2.uepg.br/index.php/olhardeprofessor> 
A contemporaneidade da Pedagogia da Autonomia de Paulo Freire frente ao "Escola Sem Partido"

Embora Paulo Freire seja conhecido e reconhecido nacional e internacionalmente pelas contribuições ao pensamento educacional, cuja vida e obra têm sido compreendidas como um binômio indissociável haja vista o comprometimento de sua produção teórica com uma prática inteiramente dedicada à educação (KOHAN, 2019), no item a seguir apresentamos brevemente apenas uma de suas obras, Pedagogia da Autonomia (1996), que iluminou nosso estudo sobre o "Anteprojeto de Lei Federal e Minuta de Justificação do Escola Sem Partido” (ESCOLA SEM PARTIDO, 2019b).

\section{A Pedagogia da Autonomia, de Paulo Freire}

Brandão (2015) qualifica que o período de vida mais importante e criativo de Paulo Freire como educador se inicia a partir dos anos finais da década de 1950 e se estende até os seus últimos dias. Nesse intervalo de cerca de 40 anos, Araújo Freire (2017) descreve que a obra pedagógica freireana se constituiu atravessando diferentes momentos histórico-políticos, que influenciaram a leitura de mundo de Freire e, consequentemente, a expressão de seu pensar, escrever e agir.

Embora advogue pela inexistência de rupturas e/ou mudanças de orientação no pensamento de Freire, a autora considera que seja possível distinguir algumas fases de sua produção. A primeira seria anterior ao exílio, representada pela tese de doutoramento intitulada Educação e atualidade brasileira (1959); a segunda, já vivendo exilado do Brasil após a instauração da ditadura militar em I964, seria notabilizada pela publicação daquela que é considerada a sua obra-prima, Pedagogia do Oprimido (1970); a terceira, nos idos de 1980, marcada fortemente pelos "livros falados", produzidos a partir de diálogos entre Freire e outros educadores; e, a quarta, referenciada no momento que sucede a passagem de Freire pela Secretaria da Educação da cidade de São Paulo, quando retoma a escrita de livros individuais. Nesse último período de produção, Freire publica, dentre outros títulos, Pedagogia da Autonomia: saberes necessários à prática educativa (1996), seu último livro em vida. Após sua morte, Ana Maria de Araújo Freire assume o papel de sucessora legal da obra freireana, dando continuidade à organização e publicação de outros escritos inéditos, poucos conhecidos ou inacabados.

No contexto desta investigação, a opção pela Pedagogia da Autonomia (1996) como referencial norteador da análise é justificada, primeiramente, pela temática central do livro, que atenta para "a questão da formação docente ao lado da reflexão sobre a prática educativo-progressiva em favor da autonomia do ser dos educandos" (FREIRE, 1996, p. 13). Compreendemos que a pretensão de ingerência do ESP sobre o trabalho docente em prol da "não doutrinação" dos discentes atribui sentidos próprios às ideias de "autonomia" e "liberdade" na educação, conceitos esses basilares da pedagogia crítico-emancipadora de Freire que mantêm, em suas definições, uma perspectiva diametral àquela defendida pelo movimento em questão.

Olhar de professor, Ponta Grossa, v. 24, p. I-24, e-II5788.039, 202I.

Disponível em <https://revistas2.uepg.br/index.php/olhardeprofessor> 
Em segundo lugar, porque neste livro ficam explicitados os esforços do educador pernambucano em reunir de forma sintética os princípios educacionais que edificou ao longo de toda sua obra (ALBUQUERQUE, 20I5), que Freire sistematiza em um conjunto de pressupostos teóricopráticos para uma pedagogia libertadora cujo fundamento é a "ética universal do ser humano" (FREIRE, 1996, p. 15). Dessa forma, consideramos, para os fins aqui propostos, que Pedagogia da Autonomia (1996) contribui para descortinar e refletir sobre a "ética menor" que orienta as ações do ESP.

O livro é aberto por um prefácio escrito por Edna Castro de Oliveira, atualmente professora e pesquisadora da Universidade Federal do Espírito Santo, que, de antemão, adverte para a incorporação da categoria da "autonomia" pelo ideário neoliberal, sublinhando a necessária atenção ao discurso ideológico e às inversões que ele opera "no pensamento e na prática pedagógica ao estimular o individualismo e a competividade" (FREIRE, 1996, p. II). Com isso, a autora pontua a dissonância entre tal perspectiva e a "autonomia" defendida por Freire ao afirmá-la como parte de uma pedagogia que anuncia "a solidariedade enquanto compromisso histórico de homens e mulheres, como uma das formas de luta capazes de promover e instaurar a "ética universal do ser humano"' (p. II). Dessa forma, Freire (1996) põe em suspeição o paradoxo autonomia/dependência ao considerar que a autonomia "se funda na responsabilidade que vai sendo assumida" (p. 94), em um processo de "amadurecimento do ser para si” pautado em "experiências respeitosas de liberdade" (p. 107).

O prefácio é seguido por uma introdução que Freire intitula "Primeiras Palavras", em que situa o objeto de sua análise, a formação docente na relação com a autonomia do educando. Desse breve texto, podemos destacar alguns aspectos que fundamentam a tese sustentada pelo autor ao longo do livro: a distinção entre "formar" e "treinar" o educando; a primazia da rigorosidade ética no ato educativo, ética essa, segundo o educador, que precisa estar comprometida com a negação do fatalismo, da exploração do ser humano, da conversão da pureza em puritanismo, da discriminação de raça, gênero e classe; a assunção do ser humano como presença no mundo, com o mundo e com os outros, cujas ações lhe conferem responsabilidade ética no mover-se no mundo; a defesa da História como tempo de possibilidade, que torna possível a problematização do futuro em face do determinismo imobilizante propagado pela ideologia neoliberal.

À continuidade, o livro se organiza em três capítulos, divididos cada um deles em nove itens referidos às exigências postas à prática educativa crítico-transformadora. No primeiro, "Não há docência sem discência", o argumento de Freire orbita em torno da relação entre educador e educando, que formam e são formados um pelo outro, dialeticamente, sem prejuízo da diferenciação que os caracteriza enquanto sujeitos. Isso o leva à recusa da concepção de ensino como um processo de transmissão de conhecimentos e conteúdos, tese essa que dá título ao segundo capítulo, "Ensinar não é transferir conhecimento", em que salienta que o ensino deve propiciar a construção do 
conhecimento pelos próprios educandos. No terceiro e último capítulo, "Ensinar é uma especificidade humana", Freire acentua a questão da autoridade docente democrática, que, segura de si, "se expressa na firmeza com que atua, com que decide, com que respeita as liberdades, com discute suas próprias posições, com que aceita rever-se" (FREIRE, 1996, p. 91).

Com base, portanto, nos pressupostos freireanos mencionados, apresentamos nos tópicos que se seguem uma proposta de leitura e análise do Anteprojeto de Lei Federal e Minuta de Justificação do Escola Sem Partido.

\section{Procedimentos metodológicos da pesquisa}

A fim de compreender e evidenciar como o ESP mobiliza, através da linguagem escrita, estratégias para avançar sobre a educação brasileira, este estudo de abordagem qualitativa se apoiou na análise do "Anteprojeto de Lei Federal e Minuta de Justificação do Escola Sem Partido versão 2.0" (ESCOLA SEM PARTIDO, 2019b), assumindo que esse documento materializou o discurso do movimento, servindo posteriormente de modelo para a redação de projetos de lei favoráveis aos seus intentos político-ideológicos.

Portanto, tendo esse se constituído como nossa fonte primária de informações, metodologicamente esta investigação se caracterizou como uma pesquisa documental, que, segundo Kripka, Scheller e Bonotto (20I5, p. 58):

[...] é aquela em que os dados obtidos são estritamente provenientes de documentos, com o objetivo de extrair informações neles contidas, a fim de compreender um fenômeno; é um procedimento que se utiliza de métodos e técnicas para a apreensão, compreensão e análise de documentos dos mais variados tipos; é caracterizada como documental quando essa for a única abordagem qualitativa, sendo usada como método autônomo.

Na pesquisa documental, afirma Flick (2009), os documentos - em geral, tomados como materiais escritos que incluem "desde leis e regulamentos, normas, pareceres, cartas, memorandos, diários pessoais, autobiografias, jornais, revistas, discursos, roteiros de programas de rádio e televisão até livros, estatísticas e arquivos escolares” (LÜDKE; ANDRÉ, 20I5, p. 45) - devem ser considerados como "meios de comunicação", em que o contexto de produção, a autoria, a utilização e as finalidades também são alvo de análise juntamente com o conteúdo. Essa perspectiva, segundo o autor, se baseia na ideia de que os documentos expressam "uma versão específica de um evento ou processo" (FLICK, 2009, p. 236) e "podem ser instrutivos para a compreensão das realidades sociais em contextos institucionais" (p. 237).

Olhar de professor, Ponta Grossa, v. 24, p. I-24, e-II5788.039, 202I. 
Bardin (2016) acrescenta que, ao receber um tratamento analítico, a informação contida no documento passa a ter uma representação diferenciada da original, sendo tal transformação mediada por procedimentos metodológicos próprios da análise documental: caracterização do documento; codificação; registros; categorização; análise crítica (KRIPKA; SCHELLER; BONOTTO, 20I5).

A análise de conteúdo do documento foi guiada pelos passos descritos por Bardin (2016): (i) leitura "flutuante" e exploração do texto selecionado; (ii) tratamento do material através de sua codificação (definição das unidades de registro e de contexto); (iii) categorização (reunião das unidades de registro sob um título genérico em razão de características comungadas por esses elementos); (iv) inferências (evidenciação e interpretação das mensagens subjacentes e relativas aos seus contextos de produção/recepção).

\section{O ESP nas entrelinhas: o que nos informa o Anteprojeto de Lei Federal e Minuta de Justificação do Escola Sem Partido}

O “Anteprojeto de Lei Federal e Minuta de Justificação do Escola Sem Partido versão 2.0" é um documento disponibilizado no formato de arquivo editável (.doc), não datado, sem assinatura que registre a autoria de sujeitos específicos e está hospedado no site do "Escola Sem Partido". Possui seis laudas e, estruturalmente, se organiza como um projeto de lei segmentado em três blocos. Inicialmente é apresentado um conjunto de doze artigos, seguido do item "Anexo", em que constam os "deveres dos professores" descritos em seis tópicos e, por fim, a justificativa que fundamenta a proposição anteriormente apresentada. Ao longo do texto, são realizadas referências à Constituição Federal de 1988, à Convenção Americana sobre Direitos Humanos e ao Estatuto da Criança e do Adolescente (ECA).

O levantamento do universo semântico empregado ao longo do texto nos permitiu identificar que termos como "direito", a partícula "não”, “ideologia/ideológico(a)”, "religião/religioso(a)", "liberdade", "moral" e "doutrinação" aparecem com frequência. Tomando este levantamento como ponto de partida, realizamos a unitarização e a categorização do documento, distinguindo a atribuição de “direitos” (Quadro I) e “deveres” (Quadro 2) que o documento propõe.

Em todas as situações, é possível notar que os sujeitos de direitos são "pais" e "estudantes", os primeiros em relação à educação moral e religiosa dos filhos e ao que é ensinado nas escolas, e os segundos, referente ao direito de não serem manipulados/doutrinados e de gravar as aulas assistidas. Salienta-se também que, quando o termo "liberdade" é conjugado a "ensinar", a ideia de direito aí implícita é substituída pela de restrição:

Liberdade de ensinar - assegurada pelo art. 206, II, da Constituição Federal - não se confunde com liberdade de expressão; não existe liberdade de expressão no

Olhar de professor, Ponta Grossa, v. 24, p. I-24, e-15788.039, 202 I.

Disponível em <https://revistas2.uepg.br/index.php/olhardeprofessor> 
exercício estrito da atividade docente, sob pena de ser anulada a liberdade de consciência e de crença dos estudantes [...].

A liberdade de ensinar obviamente não confere ao professor o direito de se aproveitar do seu cargo e da audiência cativa dos alunos, [...] nem o direito de favorecer, prejudicar ou constranger os alunos em razão de suas convicções políticas, ideológicas, morais ou religiosas; nem o direito de fazer propaganda políticopartidária em sala de aula e incitar seus alunos a participar de manifestações, atos públicos e passeatas; nem o direito de manipular o conteúdo da sua disciplina com o objetivo de obter a adesão dos alunos a determinada corrente política ou ideológica; nem, finalmente, o direito de dizer aos filhos dos outros o que é certo e o que é errado em matéria de religião e de moral;

Ante o exposto, entendemos que a melhor forma de combater o abuso da liberdade de ensinar é informar os estudantes sobre o direito que eles têm de não ser doutrinados por seus professores, a fim de que eles mesmos possam exercer a defesa desse direito, já que, dentro das salas de aula, ninguém mais poderá fazer isso por eles (ESCOLA SEM PARTIDO, 2019b).

Quadro I - Codificação do Anteprojeto de Lei Federal e Minuta de Justificação do Escola Sem Partido a partir da Categoria "Direitos”

\begin{tabular}{|c|c|}
\hline \multicolumn{2}{|r|}{ CATEGORIA “DIREITOS” } \\
\hline $\begin{array}{l}\text { Componentes } \\
\text { (unidades de } \\
\text { registro) }\end{array}$ & $\begin{array}{l}\text { Unidades de contexto } \\
\text { (exemplos) }\end{array}$ \\
\hline $\begin{array}{l}\text { Religião, religioso(a) } \\
\text { [18] }\end{array}$ & $\begin{array}{l}\text { "A liberdade de ensinar obviamente não confere ao professor [...] o direito } \\
\text { de manipular o conteúdo da sua disciplina com o objetivo de obter a } \\
\text { adesão dos alunos a determinada corrente política ou ideológica; nem, } \\
\text { finalmente, o direito de dizer aos filhos dos outros o que é certo e o que } \\
\text { é errado em matéria de religião e de moral" }\end{array}$ \\
\hline Liberdade [13] & $\begin{array}{l}\text { "A liberdade de consciência e de crença - assegurada pelo art. } 5^{\circ} \text {, VI, da } \\
\text { Constituição Federal - compreende o direito do estudante a que o seu } \\
\text { conhecimento da realidade não seja manipulado, para fins políticos e } \\
\text { ideológicos, pela ação dos seus professores". }\end{array}$ \\
\hline Moral [12] & $\begin{array}{l}\text { "respeitará o direito dos pais dos alunos a que seus filhos recebam a } \\
\text { educação religiosa e moral que esteja de acordo com as suas próprias } \\
\text { convicções". }\end{array}$ \\
\hline $\begin{array}{l}\text { Conhecer, } \\
\text { conhecimento, ciência } \\
{[6]}\end{array}$ & $\begin{array}{l}\text { "o que implica necessariamente para os pais o direito de conhecer e avaliar } \\
\text { a qualidade dos serviços prestados pelas escolas -; e do artigo } 53 \text {, par. } \\
\text { único, do ECA, que reconhece aos pais o direito de ter ciência do processo } \\
\text { pedagógico vivenciado por seus filhos". }\end{array}$ \\
\hline Gravar, gravação [4] & $\begin{array}{l}\text { "O projeto reconhece também o direito dos estudantes e dos pais de } \\
\text { gravar as aulas, caso a escola não o faça ou não disponibilize as gravações". }\end{array}$ \\
\hline Ser informado [4] & $\begin{array}{l}\text { "o direito de ser informado sobre os próprios direitos é questão de estrita } \\
\text { cidadania". }\end{array}$ \\
\hline
\end{tabular}

Fonte: Autores, 2020

Sobre os "deveres", observamos que ora são expressos como proposições afirmativas, as quais explicitam aquilo que deve ser feito tanto pelo Estado quanto pelas escolas e professores, ora como proposições negativas, que denotam um caráter proibitivo. Exemplos do primeiro caso são a 
obrigatoriedade dos professores de apresentar abordagens diversas e de forma "justa" sobre os conteúdos, de respeitar o papel dos pais quanto à educação moral e religiosa, de informar os alunos sobre o seu direito de "não doutrinação" e de fornecer um canal em que tal prática possa ser denunciada. Já dentre as principais proibições estão a menção às questões ligadas à sexualidade ("O Poder Público não se imiscuirá no processo de amadurecimento sexual dos alunos nem permitirá qualquer forma de dogmatismo ou proselitismo na abordagem das questões de gênero") e ao aproveitamento da "audiência cativa dos alunos" para doutriná-los político-ideologicamente ou constrangê-los em razão de suas próprias convicções.

Quadro 2 - Codificação do Anteprojeto de Lei Federal e Minuta de Justificação do Escola Sem Partido a partir da Categoria "Deveres"

\begin{tabular}{|c|c|}
\hline \multicolumn{2}{|r|}{ CATEGORIA “DEVERES” } \\
\hline $\begin{array}{c}\text { Componentes } \\
\text { (unidades de registro) }\end{array}$ & $\begin{array}{c}\text { Unidades de contexto } \\
\text { (exemplos) }\end{array}$ \\
\hline Ideologia, ideológico(a) [23] & $\begin{array}{l}\text { "não se aproveitará da audiência cativa dos alunos para } \\
\text { promover os seus próprios interesses, opiniões, concepções ou } \\
\text { preferências ideológicas, religiosas, morais, políticas e } \\
\text { partidárias". }\end{array}$ \\
\hline Doutrinação [7] & $\begin{array}{l}\text { "a melhor forma de combater o abuso da liberdade de ensinar é } \\
\text { informar os estudantes sobre o direito que eles têm de não ser } \\
\text { doutrinados por seus professores". }\end{array}$ \\
\hline Apresentar, entregar [4] & $\begin{array}{l}\text { "as escolas deverão apresentar e entregar aos pais ou } \\
\text { responsáveis pelos estudantes material informativo que } \\
\text { possibilite o pleno conhecimento dos temas ministrados e dos } \\
\text { enfoques adotados". }\end{array}$ \\
\hline Neutralidade [3] & $\begin{array}{l}\text { "a difusão das concepções políticas ou ideológicas de seus } \\
\text { agentes é incompatível com o princípio da neutralidade política } \\
\text { e ideológica do Estado". }\end{array}$ \\
\hline
\end{tabular}

Os números entre colchetes indicam a quantidade de vezes que o tema aparece.

Fonte: Autores, 2020.

Nos tópicos a seguir são debatidas algumas implicações da adoção desse tipo de política para a educação escolar.

\section{A preponderância dos direitos familiares e a institucionalização da perscrutação social sobre a educação escolar}

Forquin (1993) afirma que a condução da humanidade à pós-modernidade acarretou para a educação escolarizada a contestação de sua legitimidade cultural, pois a própria cultura “"perdeu seu norte' e se encontra privada das amarras da tradição e da bússola do princípio da autoridade” (p. I8).

Paradoxalmente, a dissipação das referências e do papel de transmissão cultural da escola, discutida pelo autor, parece, ao menos no Brasil, ter dado espaço à insurgência de movimentos

Olhar de professor, Ponta Grossa, v. 24, p. I-24, e-I5788.039, 202 I.

Disponível em <https://revistas2.uepg.br/index.php/olhardeprofessor> 
neoconservadores na educação, que reivindicam a precedência dos valores da família tradicional e da moral religiosa cristã. Dessa maneira, se antes era possível crer que, diante do colapso das certezas morais, a sociedade brasileira contemporânea delegava aos professores o cumprimento de funções da família e de outras instâncias sociais (PIMENTA; ANASTASIOU, 20I4), hoje assistimos uma reorientação desse processo. De um lado, o Estado neoliberal se exime do dever de zelar pela Educação e o designa cada vez mais à população (SAVIANI, 2018) e, de outro, a classe política em ascensão que reza a cartilha do fundamentalismo religioso e do mercado enaltece a prática da educação doméstica9 e negocia o controle sobre a forma e o conteúdo do que é ensinado nas escolas.

Para Souza e Oliveira (2017), uma das consequências da exigência da reprodução das convicções familiares no interior da escola é o comprometimento da distinção entre espaços formais e informais de educação e a tentativa de substituição do logos (razão) pela doxa (opinião ou crença comum) como forma predominante de conhecimento. Entretanto, para Freire (1996), uma das tarefas precípuas da prática educativo-progressista é favorecer nos estudantes a transição da "curiosidade ingênua", advinda do "saber de experiência feito", que caracteriza o senso comum, para a "curiosidade epistemológica", que resulta de procedimentos rigorosamente metódicos de aproximação ao objeto de conhecimento.

Outro aspecto levantado por Ratier (2016) é o equívoco em acreditar que a escola opere sozinha na formação de pensamento dos sujeitos. De fato, estamos imersos em um universo de informações e visões de mundo concorrentes e/ou contraditórias e, nesse contexto, a educação se desenvolve como um processo amplo e permanente na vida das pessoas.

É, pois, na contramão dessa perspectiva de transformação de pais e filhos em delatores e, desses últimos, também em vítimas do processo educacional, que resgatamos de Paulo Freire que a essência da atividade educadora é "a reinvenção do ser humano no aprendizado de sua autonomia" (FREIRE, 1996, p. 94).

O educador salienta que a urgência da democratização da escola pública passa pela formação permanente e científica de toda a comunidade escolar (educadores, vigias, merendeiras, zeladores etc.), mas de modo que "não falte sobretudo o gosto pelas práticas democráticas, entre as quais a de que

\footnotetext{
${ }^{9}$ De acordo com Barbosa (2016), a adoção da "educação doméstica" ou "ensino em casa" (homeschooling) tem endossado o encolhimento do espaço público e favorecido sua privatização. Sustentada no princípio da liberdade individual de escolha - que se opõe ao princípio da igualdade e universalidade - essa modalidade de ensino tende, na visão de Zan e Massa (2018), a agravar o quadro de desigualdade social de países em que ocorre o aprofundamento do neoliberalismo, a exemplo do Brasil. Ademais, como ressalta Carrano (2018), a escola ainda é um espaço-tempo institucional insubstituível para a experiência da pluralidade de pensamento e do diálogo entre diferentes, algo que a educação doméstica abdica taxativamente ao confinar crianças e jovens em seus recintos familiares.
} 
resulte a ingerência crescente dos educandos e de suas famílias nos destinos da escola" (FREIRE, 2019, p. 32). Com isso, se observa que, para Freire, a presença dos pais na escola deve ser estimulada, porém, dentro de um projeto de gestão democrática, algo diametralmente diferente da supremacia dos preceitos familiares desejada pelo ESP.

Ademais, Freire (1996) convida os pais à reflexão quando afirma que:

A posição da mãe ou do pai é a de quem, sem nenhum prejuízo ou rebaixamento de sua autoridade, humildemente aceita o papel de enorme importância de assessor ou assessora do filho ou da filha. Assessor que, embora batendo-se pelo acerto de sua visão das coisas, jamais tenta impor sua vontade ou se abespinha porque seu ponto de vista não foi aceito.

O que é preciso, fundamentalmente mesmo, é que o filho assuma eticamente, responsavelmente, sua decisão, fundante de sua autonomia. Ninguém é autônomo primeiro para depois decidir. A autonomia vai se constituindo na experiência de várias, inúmeras decisões, que vão sendo tomadas (FREIRE, 1996, p. 107).

Freire também alerta sobre o perigo da "tirania da liberdade" e do "exacerbamento da autoridade", ou ainda, da combinação dos dois na prática educativa. Tanto o autoritarismo quanto a licenciosidade, segundo o educador, são formas de comportamento que nos distanciam da nossa vocação ontológica para o "ser mais".

No caso do ESP, a pregação pela "liberdade" dos pais para educar moral, sexual e religiosamente seus filhos e a insinuação de que esses são "vulneráveis" à doutrinação engendrada pelos professores ocultam o caráter dissimuladamente opressor e autoritário desse discurso. Somado a isso, a assunção de que os estudantes se constituem numa "audiência cativa" e de que as gravações das aulas visam, além de garantir aos pais o conhecimento do que acontece dentro da sala de aula, "permitir a melhor absorção do conteúdo ministrado", revela o alinhamento com uma pedagogia liberal tradicional, em que o aluno é passivo no seu processo de aprendizagem e o professor é um treinador transmissor de conteúdos (LIBÂNEO, 20I4). Contudo, em contrapartida a essa pedagogia que reduz educador e educando à condição de objeto um do outro, assevera Freire (1996, p. 33) que "se se respeita a natureza do ser humano, o ensino de conteúdos não pode dar-se alheio à formação moral do educando. Educar é substantivamente formar".

Por fim, é baseado nessa defesa que Freire provoca pais e educadores a não silenciarem e negarem a curiosidade dos educandos em seu processo de aprendizagem, pois somente em um bom clima pedagógico-democrático é "que o educando vai aprendendo à custa de sua prática mesma, que sua curiosidade como liberdade deve estar sujeita a limites, mas em permanente exercício. Limites eticamente assumidos por ele" (FREIRE, 1996, p. 85). 


\title{
A retórica da neutralidade como instrumento de cerceamento da prática docente
}

A identidade docente enquanto um fenômeno individual e coletivo está sujeita a transformações constantes motivadas por diferentes fatores (PEREIRA; GIOVINAZZO JR, 2019). Segundo Lawn (200I), embora os professores se constituam como parte indispensável de uma proposta educativa, atuando como sombras, representantes ou sujeitos, o que se observa frequentemente é que, diante de um pânico moral da sociedade e das suas crianças, esses profissionais são os primeiros a serem escrutinados e reprovados. $O$ autor argumenta que essa situação conduz inevitavelmente à alteração da identidade docente sob a prerrogativa de "modernização".

No caso do Brasil, à primeira vista, poderíamos avaliar que, ao invés da modernização, o ESP estaria impondo somente um retorno ao tradicionalismo com a defesa da soberania familiar. No entanto, como afirma Girotto (2016), os articuladores dessa organização se unem às redes de privatização da Educação, e o policiamento da identidade docente os interessa para a implementação de uma escola de pensamento único que, coadunada a uma racionalidade técnica e gerencial, favoreça a execução de reformas educacionais empresariais. Pereira e Giovinazzo Jr (2019) afirmam que, nesse contexto, a identidade docente é diretamente afetada e um novo perfil de professor é imposto:

\begin{abstract}
Essa "nova" identidade define o bom professor como um profissional neutro e acrítico, um mero executor de políticas, projetos e planos educacionais, cuja ação estaria restrita ao espaço escolar ou da sala de aula, distante da vida pública e, acima de tudo, respeitador das concepções políticas e morais das famílias, mesmo quando estas se mostram contrárias aos direitos humanos e tendem a contribuir para perpetuar situações de desigualdade social e discriminações de todos os tipos (PEREIRA; GIOVINAZZO JR, 2019, p. 247).
\end{abstract}

A neutralidade, que implica certamente em um compromisso como o real existente por meio de uma defesa não declarada de sua continuidade, ganha a forma de uma "atitude ausente", que esconde as próprias posições políticas diante da ordem vigente. Esta postura é ilustrada por Lowy (1989) por meio da história de um personagem famoso de contos infantis da Alemanha, o Barão de Münchhausen, que contava vantagens e sempre relatava aventuras incríveis:

Barão de Münchhausen estava em seu cavalo quando afundou em um pantanal. $\bigcirc$ cavalo foi afundando, foi afundando, o pântano já estava quase chegando à altura do ventre do cavalo e o Barão, desesperado, não sabia o que fazer, temendo morrer ali junto ao seu cavalo. Nesse momento, ele teve uma ideia genial, simples como o ovo de Colombo: ele pegou-se pelos seus próprios cabelos e foi puxando, puxando, até tirar a si mesmo e depois o cavalo, saindo ambos, de um salto, do pantanal (LOWY, 1989, p. 43).

O ESP, ao ocultar seus próprios interesses políticos, colocando-se acima e fora do mundo social, retira-se do "pântano das ideologias", puxando-se pelos cabelos. Esta postura é qualificada por 
Gramsci (2007, p. 4I) como “ideologismo abstrato", dado pelo não reconhecimento do próprio caráter não absoluto e não eterno, a não consciência (ou deliberada ocultação) de sua parcialidade e seu vínculo orgânico a uma classe e a um momento histórico. Acerca disso, Freire insiste no imprescindível enfrentamento dessa retórica, fortemente disseminada sob o neoliberalismo, que afugenta uma ideologia própria e opera inversões ao equalizar autonomia com individualismo e competitividade. Dessa forma, o educador adverte que:

\begin{abstract}
É na diretividade da educação, esta vocação que ela tem, como ação especificamente, de endereçar-se até sonhos, ideais, utopias e objetivos, que se acha o que venho chamando de politicidade da educação. A qualidade de ser política, inerente à sua natureza. É impossível, na verdade, a neutralidade da educação. E é impossível, não porque professoras e professores "baderneiros" e "subversivos" o determinem. A educação não vira política por causa deste ou daquele educador. Ela é política. Quem pensa assim, quem afirma que é por obra deste ou daquele educador, mais ativista que outra coisa, que a educação vira política, não pode esconder a forma depreciativa como entende a política (FREIRE, 1996, p. II0).
\end{abstract}

A restrição da liberdade de cátedra dos professores imputada pelo ESP sob a alegação de que ela implica no "abuso da liberdade de ensinar" descaracteriza, de modo mais imediato, a autonomia e identidade docentes, e desmantela, em última instância, a própria razão de ser da educação quando exige que os professores sejam ausentes, esvaziados de si mesmos, de suas cores políticas e ideológicas. Por isso, Freire enfatiza sobre a impossibilidade de se estar no mundo de maneira neutra:

É exatamente por causa de tudo isso que, como professor, devo estar advertido do poder do discurso ideológico, começando pelo que proclama a morte das ideologias. $\mathrm{Na}$ verdade, só ideologicamente posso matar as ideologias, mas é possível que não perceba a natureza ideológica do discurso de que fala de sua morte. No fundo, a ideologia tem um poder de persuasão indiscutível. $O$ discurso ideológico nos ameaça de anestesiar a mente, de confundir a curiosidade, de distorcer a percepção dos fatos, das coisas, dos acontecimentos (FREIRE, 1996, p. 132, itálicos do autor).

A exigência de que sejam assegurados os direitos "do estudante de ser informado sobre os próprios direitos, visando ao exercício da cidadania" e da "liberdade de crença e consciência" são, certamente, contemplados pela educação freireana. Porém, para Freire, esse ideal somente pode se concretizar se o educador testemunha, pela sua prática, a experiência da liberdade e da autonomia:

Em nome do respeito que devo aos alunos não tenho por que me omitir, por que ocultar a minha opção política, assumindo uma neutralidade que não existe. Esta, a omissão do professor em nome do respeito ao aluno, talvez seja a melhor maneira de desrespeitá-lo. O meu papel, ao contrário, é o de quem testemunha o direito de comparar, de escolher, de romper, de decidir e estimular a assunção deste direito por parte dos educandos (FREIRE, 1996, p. 7I).

Minha presença de professor, que não pode passar despercebida dos alunos na classe e na escola, é uma presença em si política. Enquanto presença não posso ser uma omissão mas um sujeito de opções (FREIRE, 1996, p. 98, itálicos do autor).

Olhar de professor, Ponta Grossa, v. 24, p. I-24, e-15788.039, 202 I.

Disponível em <https://revistas2.uepg.br/index.php/olhardeprofessor > 
A contemporaneidade da Pedagogia da Autonomia de Paulo Freire frente ao "Escola Sem Partido"

Os deveres impositivamente definidos pelo ESP rechaçam, pela própria substância, o discurso de "pluralismo de ideias" e coíbem a expressão de uma postura ética. De fato, não se contesta que ao professor seja vedado, independentemente de sua preferência política, a transformação de sua aula em "palanque partidário". Como afirma Freire (1996), um dos saberes necessários à prática educativa é o uso do bom senso. Entretanto, clamar pela neutralidade da prática educativa é inconcebível, pois "para que a educação não fosse uma forma política de intervenção no mundo era indispensável que o mundo em que ela se desse não fosse o humano" (FREIRE, 1996, p. III).

Seguindo essa linha de raciocínio, Souza e Oliveira (2017) sublinham que a LDB prevê como parte da formação básica do cidadão a aprendizagem de temas intimamente relacionados com a dimensão política. E isso, na visão dos autores, é condizente com $\circ$ fato de convivermos e desenvolvermos relações em uma sociedade que exige o debate político por natureza. Nesse sentido, o ESP se constitui uma barreira para a construção de um ambiente democrático, uma vez que propõe enquadrar a missão política da escola como expressão de proselitismo político, de gênero e/ou religioso.

Em síntese, a negociação de direitos e deveres dos educadores se realiza tanto no âmbito da esfera política, com base no respeito à constitucionalidade defendida pelo Estado Democrático de Direito, quanto na esfera acadêmico-profissional, que opera com a formação de professores a partir de um campo de pesquisa referendado científica e socialmente.

\section{Considerações finais}

Desde 2014, o "Escola Sem Partido" tem encontrado solo fértil na realidade brasileira para impor suas pautas intrinsecamente associadas a uma agenda neoliberal. Isso se atesta pela existência de mais de 200 projetos apresentados nos diversos níveis federativos, dentre os quais, parte significativa se encontra em vigor, aprovada ou em tramitação.

A defesa da família como instituição-referência na transmissão de valores sociais e a restrição da escola a um espaço de ensino de conteúdos, por meio da deliberada interdição de temas de caráter político e moral em seu ambiente, definem, a partir dos projetos do ESP, os moldes de uma educação escolar desfigurada em relação ao seu papel de educar. Ademais, a neutralidade político-ideológica clamada pelos defensores desse movimento não encontra lugar em seus discursos, que, sob o pretexto de instaurá-la, suprimem a possibilidade da convivência com o pluralismo político principiado na Carta Magna de 1988 que rege a nação brasileira.

Ao evidenciarmos, através da análise de conteúdo do "Anteprojeto de Lei Federal e Minuta de Justificação do Escola Sem Partido versão 2.0", a postura de rejeitar os "juízos de valor" e retirar dos

Olhar de professor, Ponta Grossa, v. 24, p. I-24, e-I I5788.039, 202 I.

Disponível em <https://revistas2.uepg.br/index.php/olhardeprofessor> 
docentes as tomadas de posição sobre questões políticas, morais ou religiosas, concluímos que ocorre aos articuladores do ESP a pretensão de ocultar - deliberada ou ilusoriamente - as próprias determinações sociais e históricas de seu pensamento.

Diante desse cenário, apostamos que a obra freireana, em particular a Pedagogia da Autonomia (1996), constitui-se em um aporte crítico potencial ao enfrentamento do recrudescimento do neoconservadorismo na educação brasileira, que tem na figura do ESP um representante ativo nos dias atuais. Ante a significação sui generis atribuída por esse movimento aos conceitos de "autonomia" e "liberdade" na prática educativa, o resgate dos postulados de Freire permite revitalizar as inspirações originais de uma pedagogia da autonomia crítico-transformadora, aquela colocada a serviço da emancipação e não da domesticação humana, a favor da realização de cada indivíduo enquanto presença interventora no e com o mundo, e cimentada numa ética que se opõe àquela "ética menor, restrita, do mercado, que se curva obedientemente aos interesses do lucro" (FREIRE, 1996, p. 15).

Como últimas palavras, recuperamos a reflexão e o chamamento político-crítico-ético que Freire que nos deixa em seu último livro em vida:

Não creio que mulheres e homens, independentemente até de suas posições políticas, mas sabendo-se e assumindo-se como mulheres e homens, como gente, não aprofundem o que hoje já existe como uma espécie de mal-estar que se generaliza em face da maldade neoliberal. Mal-estar que terminará por consolidar-se numa rebeldia nova em que a palavra crítica, o discurso humanista, o compromisso solidário, a denúncia veemente da negação do homem e da mulher e o anúncio de um mundo "genteficado" serão armas de incalculável alcance (FREIRE, 1996, p. 128).

\section{Referências}

ALBUQUERQUE, T. S. Pedagogia da Autonomia: saberes necessários à prática educativa. In: SOUZA, A. I. (Org). Paulo Freire: vida e obra. 3. ed. São Paulo: Expressão Popular, 20I5. p. 203-245.

ALGEBAILE, E. Escola sem Partido: o que é, como age, para que serve. In: FRIGOTTO, G. (Org.). Escola "sem" Partido: esfinge que ameaça a educação e a sociedade brasileira. Rio de Janeiro: UERJ, LPP, 2017. p. 63-74.

ALMEIDA, R. Bolsonaro Presidente: conservadorismo, evangelismo e a crise brasileira. Novos Estudos CEBRAP, São Paulo, v. 38, n. I, P. I85-213, jan./abr. 2019. Disponível em: https://doi.org//0.2509//s01013300201900010010.

ARAÚJO FREIRE, A. M. Paulo Freire: uma história de vida. 2. ed. rev. atual. Rio de Janeiro/São Paulo: Paz e Terra, 2017.

BARBOSA, L. M. R. Homeschooling no Brasil: ampliação do direito à Educação ou via de privatização? Educação \& Sociedade, Campinas, v. 37, n. 134, p.I53-168, jan./mar. 2016. Disponível em: https://doi.org/I0.1590/ESOI0I-733020I6I572I5.

BARDIN, L. Análise de Conteúdo. São Paulo: Edições 70, 2016.

Olhar de professor, Ponta Grossa, v. 24, p. I-24, e-15788.039, 202 I.

Disponível em <https://revistas2.uepg.br/index.php/olhardeprofessor> 
BEISIEGEL, C. R. Paulo Freire. Recife: Fundação Joaquim Nabuco, Editora Massangana, 2010.

BRAIT, D. Os protagonistas do ESP. In: AÇÃO EDUCATIVA (Org.). A ideologia do movimento Escola Sem Partido: 20 autores desmontam o discurso. São Paulo: Ação Educativa, 2016. p. 161 165.

BRANDÃO, C. R. Hoje, tantos anos depois... In: SOUZA, A. I. (Org.). Paulo Freire: vida e obra. 3. ed. São Paulo: Expressão Popular, 2015. p. 7-19.

CARRANO, P. A escola pública diante do desafio de educar em relações de liberdade e convivência democrática. In: KRAWCZYK, N. (Org.). Escola pública: tempos difíceis, mas não impossíveis. Campinas: FE-CAMPINAS; Uberlândia: Navegando, 2018. p. 74-8I.

ESCOLA SEM PARTIDO. Por uma lei contra o abuso da liberdade de ensinar. 2019a. Disponível em https://www.programaescolasempartido.org/. Acesso em: 24 ago. 2019.

ESCOLA SEM PARTIDO. Anteprojeto de Lei Federal e Minuta de Justificação do Escola Sem Partido versão 2.0. 2019b. Disponível em https://www.programaescolasempartido.org/pl-federal. Acesso em: 24 ago. 2019.

ESPINOSA, B. R. S.; QUEIROZ, F. B. C. Breve análise sobre as redes do Escola sem Partido. In: FRIGOTTO, G. (Org.). Escola "sem" Partido: esfinge que ameaça a educação e a sociedade brasileira. Rio de Janeiro: UERJ, LPP, 2017. p. 49-62.

FLICK, U. Introdução à Pesquisa Qualitativa. 3 ed. Tradução: Joice Elias Costa. Porto Alegre: Artmed; Bookman, 2009.

FORQUIN, J. C. Escola e Cultura: as bases sociais e epistemológicas do conhecimento escolar. Porto Alegre: ArtMed, 1993.

FREIRE, P. Educação e atualidade brasileira. Tese (Concurso para a cadeira de História e Filosofia da Educação) - Escola de Belas-Artes de Pernambuco, Universidade do Recife, Recife, 1959.

FREIRE, P. Pedagogia da Autonomia: saberes necessários à prática educativa. 3 I. ed. Rio de Janeiro: Paz e Terra, 1996.

FREIRE, P. Pedagogia da Esperança: um reencontro com a Pedagogia do Oprimido. 25. ed. Rio de Janeiro/São Paulo: Paz e Terra, 2019.

FREIRE, P. Pedagogia do Oprimido. 17. ed. Rio de Janeiro: Paz e Terra, 1987.

GADOTTI, M. (Org.). Paulo Freire: uma biobibliografia. São Paulo: Cortez, 1996.

GIROTTO, E. Um ponto na rede: O "Escola Sem Partido" no contexto da escola do pensamento único. In: AÇÃO EDUCATIVA (Org.). A ideologia do movimento Escola Sem Partido: 20 autores desmontam o discurso. São Paulo: Ação Educativa, 2016. p. 69-76.

GRAMSCI, A. Cadernos do cárcere. 2. ed. Tradução: Carlos Nelson Coutinho. Rio de Janeiro: Civilização Brasileira, 2007. v. 4. 
HARVEY, D. Condição pós-moderna: uma pesquisa sobre as origens da mudança cultural. 23. ed. São Paulo: Edições Loyola, 2012.

KOHAN, W. Paulo Freire mais do que nunca: uma biografia filosófica. I. ed. Belo Horizonte: Vestígio, 2019.

KRIPKA, R. M. L.; SCHELLER, M.; BONOTTO, D. L. Pesquisa documental na pesquisa qualitativa: conceitos e caracterização. Revista de Investigaciones UNAP, Bogotá, v. I4, n. 2, p. 55-73, jul./dez. 2015.

LAWN, M. Os professores e a fabricação de identidades. Currículo sem Fronteiras, v. I, n. 2, p. II7-I30, jul./dez. 200I. Disponível em http://www.curriculosemfronteiras.org/voll iss2articles/lawn.pdf. Acesso em: 17 set. 2019.

LIBÂNEO, I. C. Democratização da escola pública: a pedagogia crítico-social dos conteúdos. 28. ed. São Paulo: Edições Loyola, 2014.

LÖWY, M. Ideologias e ciência social: elementos para uma análise marxista. 5. ed. São Paulo: Cortez, 1989.

LÜDKE; M.; ANDRÉ, M. E. D. A. Pesquisa em Educação: abordagens qualitativas. 2. ed. Rio de Janeiro: E.P.U., 2015.

MANHAS, C. Nada mais ideológico que "Escola Sem Partido". In: AÇÃO EDUCATIVA (Org.). A ideologia do movimento Escola Sem Partido: 20 autores desmontam o discurso. São Paulo: Ação Educativa, 2016. p. 15-2I.

MELO, J. M.; TOSTA, S. P. Mídia \& Educação. Belo Horizonte: Autêntica, 2008.

MIGUEL, L. F. Da "doutrinação marxista" à "ideologia de gênero" - Escola sem Partido e as leis da mordaça no parlamento brasileiro. Direito \& Práxis, Rio de Janeiro, v. 7, n. I5, p. 590-62I, 2016. Disponível em: https:// doi: 10.12957/dep.2016.25163.

ORO, A. P. A política da Igreja Universal e seus reflexos nos campos religioso e político brasileiros. Revista Brasileira de Ciências Sociais, v. 18, n. 53, p. 53-70, out. 2003. Disponível em: http://www.scielo.br/pdf/rbcsoc/vl8n53//8078. Acesso em: 27 ago. 2019.

PENNA, F. Entrevista concedida a Katia Machado para a reportagem Por trás do Escola sem Partido. 2018. Disponível em: http://www.epsjv.fiocruz.br/noticias/reportagem/por-tras-do-escolasem-partido. Acesso em: 10 set. 2019.

PEREIRA, E. A.; GIOVINAZZO JR, C. A.. A Identidade Docente e o Movimento Escola Sem Partido. In: GIOVANNI, L. M. (Org.). Identidades profissionais de professores: construções em curso. I. ed. Araraquara: Junqueira \& Marin, 2019. p. 243-269.

PIMENTA, S. G.; ANASTASIOU, L. G. C. Docência no Ensino Superior. 5. ed. São Paulo: Cortez, 2014.

RATIER, R. I4 perguntas e respostas sobre o "Escola Sem Partido". In: AÇÃO EDUCATIVA (Org.). A ideologia do movimento Escola Sem Partido: 20 autores desmontam o discurso. São Paulo: Ação Educativa, 2016. p. 29-4I. 
SAVIANI, D. A defesa da escola pública no Brasil: difícil, mas necessária. In: KRAWCZYK, Nora (Org.). Escola pública: tempos difíceis, mas não impossíveis. Campinas: FE-CAMPINAS; Uberlândia: Navegando, 2018. p. 23-32.

SAVIANI, D. Educação: do senso comum à consciência filosófica. II. ed. Campinas: Autores Associados, 1996.

SOUZA, A. I. (Org.). Paulo Freire: vida e obra. 3. ed. São Paulo: Expressão Popular, 2015.

SOUZA, R. F.; OLIVEIRA, T. F. A doxa e o logos na educação: o avanço do irracionalismo. In: FRIGOTTO, G. (Org.). Escola "sem" Partido: esfinge que ameaça a educação e a sociedade brasileira. Rio de Janeiro: UERJ, LPP, 20I7. p. I2I-I3I.

ZAN, D.; MASSA, D. Formação de Professores no contexto atual: os desafios apontados pelo Professor António Nóvoa. In: KRAWCZYK, N. (Org.). Escola pública: tempos difíceis, mas não impossíveis. Campinas: FE-CAMPINAS; Uberlândia: Navegando, 2018. p. I07-I I6.

ZITKOSKI, J. J. Paulo Freire \& a Educação. 2. ed. Belo Horizonte: Autêntica, 2010.

Recebido em: 03 de junho de 2020.

Versão corrigida recebida em: 05 de março de 2021.

Aceito em: 05 de março de 202I.

Publicado online em: 30 de abril de 202I. 